\title{
Empirical evidence on the long and short run determinants of health expenditure in the Arab world.
}

\author{
Karim Barkat $^{\mathrm{a}}$, Rashid Sbia ${ }^{\mathrm{b}}$, Youcef Maouchi ${ }^{\mathrm{a}}$ \\ ${ }^{\text {a }}$ Department of Economics and Finance, Qatar University, Doha (2713), Qatar. \\ ${ }^{\mathrm{b}}$ Aix-Marseille University, CNRS, EHESS, Centrale Marseille, AMSE, France
}

\begin{abstract}
:
This paper empirically examines the determinants of health care spending for 18 Arab world countries for the period 1995-2015 by using recently developed panel cointegration techniques. We conducted the same estimations for 3 sub-samples, namely high-income, upper-middle- and lower-middle-income countries to reduce the heterogeneity among them. Our empirical findings demonstrate that health care expenditure and its determinants are non-stationary, and revealed the existence of a long run relationship among variables. Furthermore, the estimation results suggest that income is not the only driver of health expenditure in the Arab world countries in the long run. Other variables such as medical progress and ageing population are also playing an important role in the increase of health care expenditure with major policy implications for the region in the long run. Furthermore, the results support that health care expenditure is a necessity good for the three income groups. Finally, the Pairwise Dumitrescu-Hurlin panel causality test shows evidence of a bidirectional causal relationship between health care expenditures and income for the full sample, as well as for the groups income.
\end{abstract}

Key words: Health expenditure, Arab world, Panel cointegration, Panel causality.

JEL Classification: I15; H51; C33; P46

Conflict of interest statement: the authors report no conflict of interest. 


\section{Introduction}

Questions about the factors that drive health care expenditures in developed countries have been widely addressed in the literature. Far less is known concerning this issue in developing countries. This study seeks to address this question in the particular context of the Arab world, marked by wars and recurring conflicts in some countries of the region, and most recently by the Arab spring revolutions which might have led to the weakening of the health sector.

During the last two decades, the Arab world countries have experienced a positive trend in per capita health spending, due to an increase in income levels, expanding economies, high incidence of lifestyle-related diseases and a growing population, accompanied with an improvement in life expectancy. The population has more than tripled since 1970, to over 354 million, while life expectancy increased from 51 years to 71 years between 1970-2010, the most important growth among world regions (Borisch, 2013). Despite these growing figures, Arab world countries have one of the lowest levels of public spending on health care as part of GDP (Bousmah, Ventelou, \& Abu-Zaineh, 2016), affecting much of their public resources for the defence and education sectors (Erdodu \& Christiansen, 2016). The total annual health care expenditure (per capita) remains insufficient in low- and middleincome countries of the Arab world and is far from meeting the health needs of the growing population. Even in the Gulf Cooperation Council countries (GCC), the richest group in the Arab world, the total health care spending was estimated at US\$ 41.6 billion in 2011 and will reach US\$ 69.4 billion by 2018 (Ram, 2014), which remains behind the developed countries in terms of per capita health spending. For example, in 2011, while the average per capita health care expenditure was around 4593 \$US in OECD countries, Qatar, the United Arab Emirates, and Kuwait registered per capita healthcare spending of 1776, 1500, and 1640 \$US, respectively (Klautzer, Becker, \& Mattke, 2014).

To cope with a growing demand for health care in the region, Arab governments have made important investments in the health sector during the last two decades. During the same period the average total health care spending per capita has risen from 719 US \$ to 1133 US \$ between 1995 and 2014, an increase of $57 \%$ (see figure 1). However, the coming decades are expected to bring significant new challenges to health care in the region due to the fluctuation in oil prices, political instability, and a growing and ageing populations. According to United Nations (2015) estimates for the 15-year period 2015-2030, the Arab world is likely to witness a population growth rate of $1.35 \%$ per annum, much higher than the growth rates projections for Southeast Asia (1.0\%), Latin America and the Caribbean $(1.0 \%)$ and East Asia and Pacific (0.5\%). All these challenges will require new strategies and considerations.

The relationship between health care expenditures and their determinants is crucial for policy makers since health care expenditures are part of the development strategies in most countries, as health outcomes go beyond the health sector, impacting the overall economy by improving labour productivity, life expectancy and general welfare (Murthy \& Okunade, 2009). In this context, the 
exploration of new insights for understanding the relationship between health expenditures and its determinants requires a deep investigation of the roles of income, technological progress and demographic structure by applying a different economic modelling approach.

Different factors led to the selection of the Arab world. First, the diversity and heterogeneity of this region have profound implications on the health status. In fact, this region includes countries with the highest per capita income in the world (Qatar ranks 1, Kuwait 6, and UAE 7) as well as those with the lowest per capita income, such as Comoros and Djibouti, which are ranked $164^{\text {th }}$ and $190^{\text {th }}$ worldwide (World Bank, 2015). Second, the rapid growth and ageing of the population, alongside with high incidences of life style diseases are driving up the health sector costs, setting a trend of a continuous increase in health spending. Third, to the best of our knowledge Yorulmaz (2016) is the only existent study that investigates the determinants of health care expenditures in the Middle East and North Africa countries $^{1}$ (MENA). Using a new approach for a panel data, the following study tries to fill the gap in the empirical literature. The results would be of interest for the researchers in the field and the Arab world health policy decision-makers.

In this paper, we use a panel data from 18 Arab world countries from 1995 to 2015, to test the existence of cointegration relationship among per capita health expenditure (THE), per capita income (GDP), mortality rate (MR) and life expectancy (LE) (as technological advance proxies, see (Dreger \& Reimers, 2005; You \& Okunade, 2017), and ageing population (POP65). To this end, we employ two different techniques: the Pooled Mean Group estimators (PMG) developed by Pesaran, Shin, \& Smith (1999), and the Pesaran's (2006) Common Correlated Effects estimator (CCE). The first estimation method (PMG) allows for heterogeneous short-term dynamics and common long run effects. The second approach (CCE) allows for heterogeneous slope coefficients across group members and crosssectional dependence among variables. Moreover, due to the heterogeneity among countries in terms of income and the significant developments of total health spending that occurred in some of these countries, the sampling method tried to fill a significant gap in the empirical literature by dividing the main sample into three sub-groups: high-income countries (GCC countries), upper-middle income and lower-middle-income countries. Finally, we investigate the direction between health expenditure and its determinants by using Pairwise Dumitrescu and Hurlin (2012) panel causality.

\footnotetext{
${ }^{1}$ Our study differs from Yorulmaz's (2016) work in several aspects. First, the author analysed the relationship between healthcare and its determinants applying a semi-parametric fixed effects regression for 16 MENA countries from 1995 to 2012, while we use more recent 1995-2014 annual panel data on 18 Arab world countries. we used cointegration techniques (PMG and CCE estimators) to investigate the long/short run relationship among our variables. Second, our study investigates several alternative technology proxies (mortality rate, life expectancy and aging population). Third, the author divided his sample into two categories (GCC and non-GCC countries), while we divide our sample into three different groups: high-income countries, upper-middle income and lower-middle-income countries, which we believe better reflect the reality.
} 
The outline of this paper is as follows: section 2 presents a brief literature review on the determinants of health spending, section 3 and 4 describe the empirical methodology and results discussion. Finally, section 5 covers the main conclusion and policy implications.

Figure 1. Evolution of total health expenditure (per capita) in Arab world

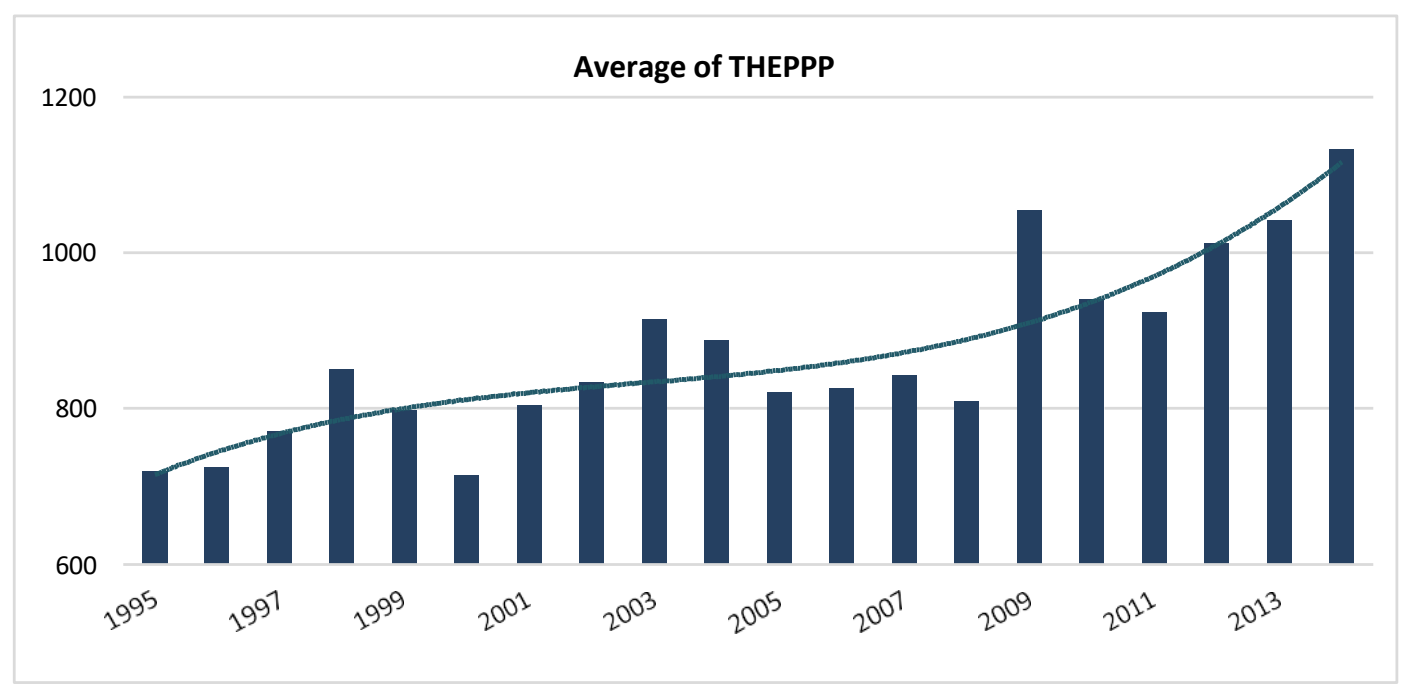

Source: Authors calculation.

\section{Literature Review}

The literature on health expenditure determinants has identified income (per capita GDP) as the most important factor explaining the variation in health expenditure among countries. There is a rich literature exploring health spending in developed countries (OECD countries) whereas very few empirical studies have focused on developing countries. As we pointed out, to the best of our knowledge, Yorulmaz (2016) is the only study that investigated the determinants of health care expenditure in MENA countries. The author analysed the relationship between healthcare spending and GDP by applying a semi-parametric fixed effects regression estimator for 16 MENA countries from 1995 to 2012. She found that income elasticity is not consistent but varies with income level, making healthcare a necessity for the non-oil rich countries and an inferior good for some GCC countries such as Kuwait, Qatar, and the United Arab Emirates.

Various studies have used panel data sets and cross-sectional data to explore the relationship between health expenditure and income in the OECD countries. Newhouse (1977), whose work pioneered the research on health care expenditures, studied 13 developed countries for the year 1971 and found that $92 \%$ of the variance in health care expenditures was explained by GDP and that income 
elasticity was larger than one. Since then, several empirical studies along those lines have been conducted using different approaches. For example, Gerdtham et al. (1992) using the annual data for 20 OECD countries over 1960-1987 period, found an income elasticity larger than one, which classifies health care as a luxury good. This result is in line with previous work such as Kleiman (1974), Newhouse (1977) and Leu (1986), as well as with subsequent studies (Freeman, 2003; Gerdtham \& Löthgren, 2002; Okunade \& Murthy, 2002; Roberts, 1999). On the other hand, Blomqvist and Carter (1997) then Baltagi and Moscone (2010), who investigated the long run relationship between income and health expenditure in 20 OECD countries over the 1971-2004 period, found that health care is a necessity good rather than a luxury good. The income elasticity was around 0.87 which was much smaller than the previous studies on OECD countries. This result was similar to the one found by Murthy \& Okunade (2016) in a study covering the 50 US states from 1960 to 2012, who found an income elasticity estimate of healthcare expenditure of 0.92 . According the these authors, health care has been evolving to become a necessity in the United States, which has also been confirmed by Murthy \& Ketenci (2017) using longer span of available time series data and considering the impact of technology. More recently, Barkat et al. (2016) using annual data on 45 Sub-Saharan countries from 1995 to 2012 and applying two methods, the Generalized Method of Moments (GMM) and the Fixed Effect Instrumental Variables (FE-IV), found that a $1 \%$ increase in real GDP leads to an average increase of $0.2 \%$ and $0.51 \%$ in health expenditure for low-income and middle-income countries, respectively. These results reveal that health is considered a necessity rather than a luxury good in the considered Sub-Saharan countries. Their conclusions are in line with previous studies such as Murthy and Okunade (2009).

The debate about the classification of health as a luxury or a necessity commodity has important policy implications. Indeed, if health is a luxury good, then market forces should be its main provider, whereas if health is found to be a necessity good, government intervention and public funding are thought to be required (Di Matteo, 2003). This debate received additional attention in light of the pressure of fiscal austerity policies enforced by several government to keep their debt sustainable (Elk, Mot, \& Franses, 2009). It is worth noting that over the last 15 years, the stationarity of the data has been taken into account when trying to explain the relationship between income and health expenditure. The potential issue with non-stationary data is the possible spurious results. To overcome this problem, several empirical studies performed different tests for stationarity and cointegration (Abdullah, Siddiqua, \& Huque, 2017; Baltagi \& Moscone, 2010; Murthy \& Ketenci, 2017; Murthy \& Okunade, 2016; Okunade, Karakus, \& Okeke, 2004; Okunade, You, \& Koleyni, 2018; You \& Okunade, 2017).

As mentioned above few studies went beyond the case of OECD countries to explore the relationship between health care expenditures and income in developing countries. Yavuz et al. (2013) considered the relationship between per capita income and per capita health expenditures in Turkey over the period 1975-2007. Their results show that income has no effect on health expenditures in the long run, and that it is a necessity good in the short run, with a $1 \%$ increase in per capita income creating a $0.75 \%$ increase in per capita health expenditures. Moreover, the percentage of older people has positive effect 
on health expenditures in both short and long runs. Considering the case of 5 Asian countries (Indonesia, Malaysia, the Philippines, Singapore and Thailand), Tang and Ch'ng (2011) found that health expenditure and income are cointegrated except in the cases of Malaysia and the Philippines. Moreover, they show that the relationship is unidirectional running from income to health expenditure, except for Indonesia where the relationship is neutral. This unidirectional causality running from per capita GDP to health care expenditure is confirmed, in the short run, by Khan et al. (2016) who studied the South Asian Association for Regional Cooperation (SAARC) countries over the period 1995-2012. The authors find an income elasticity of health care expenditure of less than unity in both the long run and the short run. This results is confirmed on the long run by Abdullah, Siddiqua, \& Huque (2017) using a panel data covering 36 Asian countries for the period 1995-2013, who found that health care is a necessity good. Chaabouni \& Abednnadher (2014) examining the determinants of health expenditures in Tunisia over the period 1961-2008, show that health care is a necessity rather than a luxury good and that the relationship is bidirectional both in the short and the long run. The bidirectional relationship between health expenditure and economic growth is also the conclusion of Nasiru \& Usman (2012) for Nigeria over the period of 1980-2010. Lv \& Zhu (2014) analyse the relationship between per capita HCE and per capita GDP in 42 African countries over the period 1995-2009 and found that the income elasticity is not constant but varies with income level, and health care is a necessity rather than a luxury for African countries.

Beyond the effect of income on health care expenditures, other variables have been identified in the literature as determinants of health spending. The population's age structure, for instance, has been mainly used to explain the variation in health spending across countries. The share of young (population under 15 years) and old people (population above 65 years) are commonly incorporated in the health expenditure regressions to characterize the dependency rates of the populations. The effect of these variables on health care expenditure are mixed: while some authors find positive effects (Barkat et al., 2016; Okunade et al., 2004), others find statistically insignificant effects (Di Matteo \& Di Matteo, 1998; Gerdtham \& Jönsson, 2000; Hitiris \& Posnett, 1992; Jönsson \& Eckerlund, 2003; Leu, 1986). Additionally, technological progress, although difficult to measure, has also been used to explain variations in health spending across countries and regions. To capture the technological progress effect, different proxies have been incorporated in the regression models, such as the surgical procedures, the number of specific medical equipment (Baker \& Wheeler, 1998), research and development funding intended to the health sector (Murthy \& Ketenci, 2017; Okunade \& Murthy, 2002; You \& Okunade, 2017), international co-operation patents (Okunade et al., 2018), life expectancy and infant mortality (Dreger \& Reimers, 2005; You \& Okunade, 2017), or time index (Gerdtham \& Löthgren, 2000). Government expenditures have also been identified by the literature as another driver of health care expenditure. Nevertheless, the empirical literature shows that there is no consensus on the effect of government spending on health: while Okunade et al. (2004) and Moscone and Tosetti (2010) found that it had a negative effect on health expenditure, Leu (1986), Culyer (1988) and Hitiris and Posnett (1992) have reached the opposite conclusion. 
The interactions of health care expenditures with other variables such as education expenditures has also been at the centre of various studies such as Rahman (2011) who considered the case of Bangladesh, Mehmood, Raza, \& Mureed (2014) on a sample of 26 Asian countries, Hirnissa (2009) who investigated the inter-relationship between military, education, and health expenditure in eight Asian countries, Tang \& Lai (2011) the case of Malaysia, or Hassan \& Kalim (2012) for Pakistan. More recently, different authors have also been linking health spending and environment, and investigate the impact of $\mathrm{CO}^{2}$ emissions and emissions of pollutants on health spending (See for instance Chaabouni $\&$ Saidi (2017)).

\section{Data, Model, and Methodology}

\subsection{Data and Model:}

The dataset used in this paper was collected from two sources. The World Development Indicators (WDI) of the World Bank and the World Health Organization (National Health Accounts, NHA). Our empirical analysis uses annual panel data of 18 Arab world countries observed over the period of 1995 $2015^{2}$. Total health expenditure (THE) and income (GDP) variables are expressed in per capita measured by constant US Dollars (2010) based on purchasing power parity (PPP). We expect a positive and significant relationship between these two variables. Mortality rate (MR), life expectancy (LE) and ageing population (population above 65 years, POP65) variables, are used as proxies for technological progress (Dreger \& Reimers, 2005; You \& Okunade, 2017). As a response to technological progress, we expect positive coefficients for life expectancy and ageing population, while mortality rate coefficient is expected to be negative.

Given the heterogeneity among the considered countries in our study and to better investigate different elasticities of our variables, we classified the studied sample into three main groups using the World Bank (2016) country classification. The first group includes the high-income countries where the GNI per capita is equal to $\$ 12,476$ or more (Qatar, Oman, Saudi Arabia, Kuwait, Bahrain, United Arab Emirates). The second group is composed of the upper-middle-income countries where the GNI per capita is between $\$ 4,036$ and $\$ 12,475$ (Algeria, Libya, Lebanon and Jordan). Finally, the lower-middle income group is composed of countries with a GNI per capita between $\$ 1,026$ and $\$ 4,035$ (Comoros, Djibouti, Egypt, Mauritania, Morocco, Tunisia, Sudan and Yemen).

The general form of the total health expenditure function is constructed as follows:

$$
\text { THE }=f(G D P, \text { MR, LE, POP65) }
$$

We have converted all the variables into a natural logarithmic form to allow us to interpret them as elasticities. Due to the different measures of technological progress, four specifications (S1, S2, S3, and S4) models are estimated:

\footnotetext{
${ }^{2}$ We used a short period (1995-2015) due to the unavailability of data for Arab world countries.
} 


$$
\begin{aligned}
& \text { (S1): } \mathrm{LTHE}=\alpha_{1}+\alpha_{2} L G D P_{i t}+\alpha_{3} L M R_{i t}+\varepsilon_{t} \ldots \ldots \ldots \ldots \ldots \ldots . .(2) \\
& \text { (S2): } \mathrm{LTHE}=\alpha_{1}+\alpha_{2} L G D P_{i t}+\alpha_{3} L L E_{i t}+\varepsilon_{t} \\
& \text { (S3): } \mathrm{LTHE}=\alpha_{1}+\alpha_{2} L G D P_{i t}+\alpha_{3} L P O P 65_{i t}+\varepsilon_{t} \\
& \text { (S4): } \mathrm{LTHE}=\alpha_{1}+\alpha_{2} L G D P_{i t}+\alpha_{3} L M R_{i t}+L P O P 65_{i t}+\varepsilon_{t} \ldots \text { (5) }
\end{aligned}
$$

It is worth noting that in the fourth specification (equation 5) mortality rate (LMR) is considered as a technology proxy while ageing population variable (LPOP65) as a demographic measure (You \& Okunade, 2017). We include mortality rate instead of life expectancy in equation 5 because the life expectancy variable includes the effect of ageing population, as both of these variables are highly correlated with each other (Murthy \& Ketenci, 2017).

\subsection{Methodology}

The empirical procedure followed in this study consists of six steps. First, we start by testing for crosssection dependence among the considered variables using the cross-sectional dependence test (CD) of Pesaran (2004). It is important to investigate the residual cross-sectional dependence in order to conduct an accurate panel unit root test and select the suitable panel estimation method. Based on the results of the results of this first step and if the cross-section dependence is confirmed, we use in a second step, the second generation panel unit root tests, the CADF and the CIPS tests suggested by Pesaran (2007) that accounts for cross-sectional dependence. In a third step, we test the slope homogeneity using the delta test developed by Pesaran \& Yamagata (2008). The fourth step will consist in checking for panel cointegration using Westerlund (2007) test to examine the long-term relationship between total health expenditure and its determinants. Fifth, we preform our estimation using the Common Correlated Effects (CCE) estimation of Pesaran (2006) that allows for heterogeneous slope coefficients across group members and cross sectional dependence among variables. We also use PMG estimator that allows for the heterogeneity of the short-run coefficients. Finally, we check the robustness of our results by performing the panel causality test of Dumitrescu-Hurlin (2012) in heterogeneous panels.

\subsubsection{Cross-sectional dependence and panel unit root tests}

A number of unit root tests are used in the empirical literature to examine the properties of time series variables (stationary or nonstationary). These tests include country specific time series and panel unit root tests. The first generation of panel unit root tests rely on the assumption of a cross-section independence of the considered data. This assumption can lead to biased estimations and tests if cross-section dependence is not incorporated. To avoid these methodological drawbacks, we use the cross-sectional dependence test (CD) proposed by Pesaran (2004) to investigate the residual cross-sectional dependence. Our results, 
reported in table 1, support the presence of cross-sectional dependence for the whole panel, as well as for each of the three income groups.

Table 1: Cross sectional dependence tests (Pesaran, 2004)

\begin{tabular}{|c|c|c|c|c|c|c|c|c|}
\hline & \multicolumn{2}{|c|}{ Whole Sample } & \multicolumn{2}{|c|}{ GCC } & \multicolumn{2}{|c|}{ UMI } & \multicolumn{2}{|c|}{ LMI } \\
\hline & $\begin{array}{l}\mathrm{CD} \\
\text { test }\end{array}$ & $\begin{array}{c}\mathrm{p}- \\
\text { value }\end{array}$ & $\begin{array}{l}\mathrm{CD} \\
\text { test }\end{array}$ & $\begin{array}{c}\mathrm{p}- \\
\text { value }\end{array}$ & $\begin{array}{l}\mathrm{CD} \\
\text { test }\end{array}$ & $\begin{array}{c}\mathrm{p}- \\
\text { value }\end{array}$ & $\begin{array}{l}\mathrm{CD} \\
\text { test }\end{array}$ & $\begin{array}{c}\mathrm{P}- \\
\text { value }\end{array}$ \\
\hline LTHE & 25.80 & 0.00 & 10.76 & 0.00 & 3.63 & 0.00 & 18.40 & 0.00 \\
\hline LLE & 45.97 & 0.00 & 17.45 & 0.00 & 11.02 & 0.00 & 23.41 & 0.00 \\
\hline LGDP & 11.89 & 0.00 & -1.70 & 0.08 & 3.61 & 0.32 & 11.45 & 0.00 \\
\hline LPOP65 & 3.58 & 0.00 & -0.55 & 0.51 & 11.04 & 0.00 & -1.60 & 0.11 \\
\hline LMR & 54.75 & 0.00 & 17.27 & 0.00 & 11.15 & 0.01 & 23.26 & 0.00 \\
\hline $\begin{array}{l}\text { Number } \\
\text { groups }\end{array}$ & \multicolumn{2}{|c|}{18} & \multicolumn{2}{|c|}{06} & \multicolumn{2}{|c|}{04} & \multicolumn{2}{|c|}{08} \\
\hline
\end{tabular}

Notes: Under the null hypothesis of cross-section independence $\mathrm{CD} \sim \mathrm{N}(0,1)$

Given the existence of cross-section dependence, we examine the residual stationarity using the second generation panel unit root test introduced by Pesaran $(2007)^{3}$. This test extends the standard augmented Dickey-Fuller (ADF) (1979) regressions to account for the existence of cross-section dependence (common factors). Standard ADF regressions are developed by adding lagged levels of cross-sectional averages $\left(\bar{y}_{t-1}\right)$ and first differences of the individual series. The cross-sectionally augmented Dickey-Fuller $(\mathrm{CADF})$ regression can be written as follow:

$$
\Delta y_{i t}=\alpha_{i}+\beta_{i} y_{i, t-1}+\gamma_{i} \bar{y}_{t-1}+\delta_{i} \Delta \bar{y}_{t}+\varepsilon_{i t}
$$

where $\bar{y}_{t}$ is the average at time $t$ of all $\mathrm{N}$ observations, and is included in the equation as a proxy of the unobserved common factors effect (Pesaran, 2006, 2007). According to Pesaran (2007), the unit root test can be performed on the t-value of $\beta_{i}$, either individually or in a combined way. Building on the test of Im, Pesaran and Shin (2003) (IPS), the test suggested by Pesaran (2007) is a cross-sectional augmented version of the IPS-test. The test suggested by Im, Pesaran and Shin (2003), is based on the assumption of crosssectional independence, and allows for heterogeneity of individual deterministic effects (constant and/or trend) and heterogeneous serial correlation structure of the error terms. Pesaran (2007) is considered as a cross-sectional augmented IPS (CIPS) test, which is a simple average of the individual CADF-tests.

$$
\operatorname{CIPS}(N, T)=\frac{1}{N} \sum_{i=1}^{N} C A D F_{t-j}
$$

\footnotetext{
${ }^{3}$ As we mentioned above, the short time series dimension of our panel, implies that we did not take into account the presence of structural breaks in the data.
} 
The results of the CADF and CIPS panel unit root tests for each of the variables are reported in Table 2. We performed each test to the level and first difference of each variable. The results indicate that all variables for the whole panel and subgroups are integrated of order one, I(1).

Table 2: Panel unit root test with cross-section dependence

\begin{tabular}{|c|c|c|c|c|}
\hline \multirow[b]{2}{*}{ Whole sample } & \multicolumn{2}{|c|}{ Level } & \multicolumn{2}{|c|}{ Difference } \\
\hline & CADF & CIPS & CADF & CIPS \\
\hline LTHE & -1.15 & -1.99 & $-2.49 * * *$ & $-3.95 * * *$ \\
\hline$L G D P$ & -1.09 & -1.18 & $-2.71 * * *$ & $-3.04 * * *$ \\
\hline LPOP65 & -1.17 & -0.60 & $-2.05^{*}$ & $-3.07 * * *$ \\
\hline$L M R$ & -1.52 & -1.08 & $-2.69 * * *$ & $-2.81 * * *$ \\
\hline$L L E$ & -1.92 & -1.23 & $-2.75 * * *$ & $-2.78 * *$ \\
\hline GCC & CADF & CIPS & CADF & CIPS \\
\hline LTHE & -2.02 & -1.15 & $-2.97 * * *$ & $-3.50 * * *$ \\
\hline$L G D P$ & -1.28 & -1.70 & $-2.88 * * *$ & $-3.07 * * *$ \\
\hline LPOP65 & -1.38 & -1.02 & $-2.84 * * *$ & $-3.10 * * *$ \\
\hline$L M R$ & -1.62 & -1.19 & $-2.71 * * *$ & $-3.12 * * *$ \\
\hline$L L E$ & -1.29 & -1.58 & $-3.57 * * *$ & $-4.99 * * *$ \\
\hline UMI & CADF & CIPS & CADF & CIPS \\
\hline LTHE & -1.97 & -0.22 & $-3.00 * * *$ & $-3.00 * * *$ \\
\hline$L G D P$ & -0.23 & -2.01 & $-2.79 * * *$ & $-2.76 * * *$ \\
\hline LPOP65 & -1.90 & -1.73 & $-2.87 * * *$ & $-2.90 * * *$ \\
\hline$L M R$ & -0.45 & -1.52 & $-2.55^{* *}$ & $-2.88 * * *$ \\
\hline$L L E$ & -1.10 & -1.43 & $-2.46 * * *$ & $-3.17 * * *$ \\
\hline LMI & CADF & CIPS & CADF & CIPS \\
\hline LTHE & -1.99 & -1.20 & $-3.28 * * *$ & $-3.84 * * *$ \\
\hline$L G D P$ & -1.18 & -1.11 & $-2.77 * * *$ & $-3.30 * * *$ \\
\hline LPOP65 & -0.60 & -1.63 & $-2.75^{* * *}$ & $-2.97 * * *$ \\
\hline$L M R$ & -2.08 & -0.75 & $-2.81 * * *$ & $-3.26 * * *$ \\
\hline$L L E$ & -1.01 & -0.69 & $-2.32 * *$ & $-2.15^{*}$ \\
\hline
\end{tabular}

\subsubsection{Homogenous Test for the Cointegration Coefficients:}

After examining the cross-sectional dependence among the variables and checking for the stationarity of our data, the next step in our analysis is to test whether the slope coefficients in the cointegration equation are homogeneous or not. This test is important in a panel data analysis for selecting the right panel estimation method, and heterogeneous panel Granger causality test. Assuming homogenous slope coefficients, while the coefficients are heterogeneous may led to biased results (Breitung, 2005). We will use the test developed by Swamy (1970) and then enhanced by Pesaran and Yamagata (2008). The 
cointegration equation (8) used to test whether the slope coefficients, $\gamma_{i}$, differ across sections ca be written as follow:

$$
Y_{i t}=\alpha+\gamma_{i} X_{i t}+\varepsilon_{i t}
$$

Hypotheses of the homogeneity test are;

$H_{0}: \gamma_{i}=\gamma$ Slope coefficients are homogenous.

$H_{1}: \gamma_{i} \neq \gamma$ Slope coefficients are heterogeneous.

Pesaran and Yamagata (2008) developed two different test statistics to test the hypotheses.

$$
\begin{aligned}
& \widehat{\Delta}=\sqrt{N} \frac{N^{-1} \widehat{N}-K}{\sqrt{2 K}} \\
& \widehat{\Delta_{a d \jmath}}=\sqrt{N} \frac{N^{-1} \widehat{N}-K}{\sqrt{\operatorname{var}(T, K)}}
\end{aligned}
$$

Where, $N$ is the cross section number, $S$ is the Swamy test statistics, $k$ shows explanatory variable number, and $\operatorname{Var}(\mathrm{t}, \mathrm{k})$ indicates standard error.

Our results, reported in table 3 , show that we cannot accept $H_{0}$ as the probability value is less than $5 \%$. We therefore accept the alternative hypothesis, which means that the slope coefficients are heterogeneous for the whole panel, and the subgroups.

Table 3. Homogenous Test.

\begin{tabular}{lcccc}
\hline & Panel & GCC & UMI & LMI \\
\hline Models & $\hat{\Delta}_{a d j}$ & $\widehat{\Delta}_{a d j}$ & $\widehat{\Delta}_{a d j}$ & $\widehat{\Delta}_{a d j}$ \\
S1.IMCOME-LMR & $61.56^{* * *}$ & $11.76^{* * *}$ & $9.45^{* * *}$ & $21.23^{* * *}$ \\
S2.INCOME- LLE & $77.78^{* * *}$ & $17.98^{* * *}$ & $8.34^{* * * *}$ & $54.34^{* * *}$ \\
S3.INCOME-LOP65 & $82.23^{* * *}$ & $9.34^{* * * *}$ & $12.56^{* * *}$ & $35.45^{* * *}$ \\
S4.INCOME-LMR-LPOP65 & $95.90^{* * *}$ & $4.34^{* * *}$ & $9.23^{* * *}$ & $11.45^{* * *}$ \\
\hline
\end{tabular}

Note: $* * *$ and $* * *$ denote statistical significance at the $1 \%, 5 \%$ and $10 \%$ levels, respectively. $H 0: \beta i=\beta$ Slope coefficients are homogenous. $H 1: \beta i \neq \beta$ Slope coefficients are heterogeneous.

\subsubsection{Westerlund (2007) panel cointegration test:}

In this step we will test for panel cointegration, using the Westerlund (2007) cointegration tests. This test provides a new simple residual-based panel cointegration test that allows for cross-sectional dependence among the different groups in the panel. Westerlund established four panel cointegration tests $\left(G_{t}, G_{a}, P_{t}\right.$, $P_{a}$ ) based on the Error Correction Model (ECM) to assess the null hypothesis of no cointegration. Two different groups of these tests are implemented: group mean tests and panel tests. These tests inspect whether cointegration is existent or not by determining whether error-correction is present for individual groups of the panel and for the panel as a whole. Westerlund's (2007) tests are based on the following error correction model: 


$$
\Delta y_{i t}=\delta_{i}^{\prime} d_{t}+\alpha_{i} y_{i, t-1}-\beta_{i}^{\prime} x_{i, t-1}+\sum_{j=1}^{p_{i}} \alpha_{i j} \Delta y_{i, t-j}+\sum_{-q_{i}}^{p_{i}} \gamma_{i j} \Delta x_{i, t-j}+\mu_{i t}
$$

where $\boldsymbol{\alpha}_{\boldsymbol{i}}$ indicates the speed of adjustment toward the long-run equilibrium for group $i$, or the error correction term. The null hypotheses of no cointegration for the panel test can be expressed as $H_{0}: \alpha_{i}=0$ , and the rejection of this hypothesis infers an evidence of cointegration for the panel as a whole. Similarly, the null hypothesis of no cointegration for the group mean tests implies that the convergence toward the long run equilibrium is heterogeneous across the different groups. In contrast, the rejection of the null hypothesis provides an evidence of cointegration (the convergence toward the long run equilibrium is homogenous).

The results of Westerlund (2007) test for the four blocs group are reported in Table 4. According to the empirical results given in table 4 for the whole panel and the subgroups, the null hypothesis is rejected indicating the existence of a long run relationship between total health expenditure and its determinants for the 4 specifications models.

Table 4: Westerlund (2007) cointegration tests.

\begin{tabular}{lllllllll}
\hline & \multicolumn{2}{c}{$\boldsymbol{G}_{\boldsymbol{t}}$} & \multicolumn{2}{c}{$\boldsymbol{G}_{\boldsymbol{a}}$} & \multicolumn{2}{c}{$\boldsymbol{P}_{\boldsymbol{t}}$} & \multicolumn{2}{c}{$\boldsymbol{P}_{\boldsymbol{a}}$} \\
\hline Whole Sample & Z-value & $\mathrm{p}$-value & Z-value & $\mathrm{p}$-value & Z-value & $\mathrm{p}$-value & Z-value & $\mathrm{p}$-value \\
\hline S1. & -2.15 & 0.01 & 1.98 & 0.97 & -1.48 & 0.06 & -0.08 & 0.46 \\
S2. & -5.20 & 0.00 & 2.47 & 0.99 & -3.06 & 0.00 & 0.59 & 0.72 \\
S3. & -1.97 & 0.02 & 1.28 & 0.90 & -1.41 & 0.07 & -0.60 & 0.27 \\
S4. & -2.70 & 0.00 & 2.72 & 0.99 & -1.97 & 0.02 & 1.25 & 0.89 \\
GCC & & & & & & & & \\
\hline S1. & -2.19 & 0.01 & 1.53 & 0.93 & -2.79 & 0.00 & -0.05 & 0.45 \\
S2. & -2.89 & 0.00 & 1.63 & 0.93 & -2.07 & 0.01 & 0.13 & 0.55 \\
S3. & -8.22 & 0.00 & 2.50 & 0.99 & -1.44 & 0.07 & 1.08 & 0.86 \\
S4. & -3.43 & 0.00 & 2.16 & 0.98 & -1.73 & 0.04 & 0.55 & 0.70 \\
UMI & & & & & & & & \\
\hline S1. & -2.61 & 0.00 & 1.47 & 0.93 & -1.46 & 0.07 & 0.57 & 0.71 \\
S2. & -5.83 & 0.00 & 1.70 & 0.95 & -3.71 & 0.00 & 0.33 & 0.63 \\
S3. & -3.06 & 0.00 & 0.72 & 0.76 & -2.46 & 0.00 & -076 & 0.22 \\
S4. & -3.12 & 0.00 & 2.14 & 0.98 & -2.47 & 0.00 & 0.81 & 0.79 \\
LMI & & & & & & & & \\
\hline S1. & -2.95 & 0.00 & 1.77 & 0.96 & -2.04 & 0.02 & 0.47 & 0.47 \\
S2. & -4.15 & 0.00 & 2.51 & 0.99 & -1.86 & 0.03 & 1.00 & 0.84 \\
S3. & -2.79 & 0.00 & -0.41 & 0.34 & -2.00 & 0.02 & -1.03 & 0.15 \\
S4. & -2.00 & 0.00 & 1.39 & 0.91 & -1.40 & 0.08 & 0.94 & 0.82 \\
\hline
\end{tabular}

H0: no cointegration; Gt and Ga test the cointegration for each country individually, and Pt and Pa test the cointegration of the panel as whole.

\subsubsection{Methods of estimation:}

In this study we use two panel estimators, namely, the Pooled Mean Group (PMG) developed by Pesaran, Shin, and Smith (1999) and the Pesaran's (2006) Common Correlated Effects (CCE).

The first technic involves both averaging and pooling in its estimation procedure. The advantage of this technique is that it allows the heterogeneity of the parameters in health regressions as it allows heterogenous 
short-term dynamics and error variances across groups but considers common long run effects. The PMG estimator is constructed as follows:

$$
\Delta Y_{i t}=\varnothing Y_{i t-1}+\beta_{i} X_{i t}+\sum_{j=1}^{p i-1} \gamma_{i j} \Delta Y_{i, t-j}+\sum_{j=0}^{q i-1} \delta_{i j} \Delta X_{i, t-j}+\mu_{i}+\theta_{i} t+\varepsilon_{i t}
$$

where $Y_{i t}$ is the dependent variable, $X_{i t}$ is a vector of explanatory variables, $\mu_{i}$ is the country-specific intercepts and $\theta_{i} t$ represents the time trend parameter, $\gamma_{i j}$ and $\delta_{i j}$ include the country-specific coefficients of the short-term dynamics, $\varepsilon_{i t}$ is a white noise error term.

The second technic (CCE) developed by Pesaran (2006) takes into account the slope heterogeneity, the cross-sectional dependence and the unobserved common factors. The idea of common correlated effects estimation is to approximate the projection space of the unobserved common factors with the inclusion of cross section averages of the variables in the regression equation. The CCE estimator is constructed as follows:

$$
\begin{aligned}
& Y_{i t}=\alpha_{i} Y_{i t-1}+\beta_{i} X_{i t}+\mu_{i t} \\
& \mu_{i t}=C_{y i}+\gamma_{i} F_{t}+\epsilon_{i t} \\
& X_{i t}=C_{x i}+T_{i} F_{t}+\omega_{i t}
\end{aligned}
$$

Where $Y_{i t}$ and $X_{i t}$ are observables, while the error term $\mu_{i t}$ and the vector of regressors $X_{i t}$ are both determined by the individual specific fixed effects $C_{y i}$ and $C_{x i}$, and an $m \times 1$ vector of unobserved common factors $F_{t}$. The factor loadings are given by $\mathrm{Ci}=\left(\gamma_{i} ; T_{i}\right) . \epsilon_{i t}$ and $\omega_{i t}$ are the idiosyncratic error terms.

\section{Empirical results and discussion}

The empirical results of the PMG and CCE estimators, describing the long-run relationship between total health expenditure and its determinants for the full and sub-samples are presented in the Table 5.

As expected, the income elasticity is positive and significant in both estimations for the full sample. Moreover, the income coefficients are less than 1, indicating that health care is a necessity rather than a luxury good in the considered Arab world countries, which is in line with Yorulmaz (2016). It is important to note that income coefficients in the CCE estimator are smaller than in the case of PMG. This result could be explained by the robustness of the CCE estimator to the cross-sectional dependence and heterogeneity slope.

The estimated coefficients of the technological effect, proxied by life expectancy and ageing population, in the two models S2 and S3 are also positive and significants in both estimations. We observe that the mortality rate coefficient in the $\mathrm{S} 1$ model is negative and significant. This means that medical progress materializes through an increase of ageing population and life expectancy, or a decrease of infant mortality. Moreover, ageing population variable in S4 model, considered as a demographic measure, is positive and significant, suggesting that ageing population leads to an increase in total health spending in the long run in the Arab world countries. Our results differ from Yorulmaz (2016) for whom the population over 65 years seems to have no significance. Our results imply that in the long run, ageing population will progressively have major economic and health implications in the Arab world countries. 
An elderly population would increase health care costs and influence the health industry structure in terms of type of services and medical health care workers needed, such as home care.

Table 5. Pooled Mean Group (PMG) and Common Correlated Effects Estimation estimators .

\begin{tabular}{|c|c|c|c|c|c|c|c|c|}
\hline \multirow[b]{2}{*}{ Models } & \multicolumn{2}{|c|}{ PANEL } & \multicolumn{2}{|c|}{ GCC } & \multicolumn{2}{|c|}{ UMI } & \multicolumn{2}{|c|}{ LMI } \\
\hline & PMG & $\mathrm{CCE}$ & PMG & $\mathrm{CCE}$ & PMG & $\mathrm{CCE}$ & PMG & $\mathrm{CCE}$ \\
\hline \multicolumn{9}{|l|}{ S1.LMR } \\
\hline Income elasticity & $\begin{array}{l}0.78 * * * \\
(0.12)\end{array}$ & $\begin{array}{l}0.37 * * * \\
(0.05)\end{array}$ & $\begin{array}{l}0.77 * * * \\
(0.01)\end{array}$ & $\begin{array}{l}0.73 * * * \\
(0.01)\end{array}$ & $\begin{array}{l}0.60 * * * \\
(0.11)\end{array}$ & $\begin{array}{l}0.58 * * * \\
(0.20)\end{array}$ & $\begin{array}{l}0.79 * * * \\
(0.01)\end{array}$ & $\begin{array}{l}0.70 * * * \\
(0.01)\end{array}$ \\
\hline Technological Effect & $\begin{array}{l}-0.64 * * \\
(0.08)\end{array}$ & $\begin{array}{l}-0.81 * * \\
(0.04)\end{array}$ & $\begin{array}{l}-0.55^{* *} \\
(0.07)\end{array}$ & $\begin{array}{l}-0.20 * * \\
(0.09)\end{array}$ & $\begin{array}{l}-1.18^{* * *} \\
(0.44)\end{array}$ & $\begin{array}{l}-0.39 * * \\
(0.15)\end{array}$ & $\begin{array}{l}-2.56^{* * *} \\
(0.02)\end{array}$ & $\begin{array}{l}-0.18 * * \\
(0.02)\end{array}$ \\
\hline \multicolumn{9}{|l|}{ S2.LLE } \\
\hline Income elasticity & $\begin{array}{l}0.54 * * * \\
(0.12)\end{array}$ & $\begin{array}{l}0.29 * * * \\
(0.11)\end{array}$ & $\begin{array}{l}0.63 * * * \\
(0.00)\end{array}$ & $\begin{array}{l}0.29 * * * \\
(0.04)\end{array}$ & $\begin{array}{l}0.38 * * \\
(0.04)\end{array}$ & $\begin{array}{l}0.24 * * * \\
(0.00)\end{array}$ & $\begin{array}{l}0.75 * * * \\
(0.21)\end{array}$ & $\begin{array}{l}0.61 * * * \\
(0.11)\end{array}$ \\
\hline Technological Effect & $\begin{array}{l}7.18 * * * \\
(0.78)\end{array}$ & $\begin{array}{l}3.59 * * * \\
(0.61)\end{array}$ & $\begin{array}{l}0.11 * * * \\
(0.00)\end{array}$ & $\begin{array}{l}1.68 * * * \\
(0.32)\end{array}$ & $\begin{array}{l}0.66^{* * *} \\
(0.10)\end{array}$ & $\begin{array}{l}1.00 * * \\
(0.00)\end{array}$ & $\begin{array}{l}0.80 * \\
(1.05)\end{array}$ & $\begin{array}{l}1.74 * * * \\
(0.61)\end{array}$ \\
\hline \multicolumn{9}{|l|}{ S3.POP65 } \\
\hline Income elasticity & $\begin{array}{l}0.92 * * * \\
(0.10)\end{array}$ & $\begin{array}{l}0.90 * * * \\
(0.01)\end{array}$ & $\begin{array}{l}0.86 * * * \\
(0.49)\end{array}$ & $\begin{array}{l}0.53 * * * \\
(0.18)\end{array}$ & $\begin{array}{l}0.68 * * \\
(0.03)\end{array}$ & $\begin{array}{l}0.59 * * * \\
(0.03)\end{array}$ & $\begin{array}{l}0.63 * * * \\
(0.04)\end{array}$ & $\begin{array}{l}0.51 * * \\
(0.02)\end{array}$ \\
\hline Technological Effect & $\begin{array}{l}0.28 * * * \\
(0.17)\end{array}$ & $\begin{array}{l}0.56 * * * \\
(0.05)\end{array}$ & $\begin{array}{l}0.75 * * * \\
(0.28)\end{array}$ & $\begin{array}{l}1.17 * * * \\
(1.83)\end{array}$ & $\begin{array}{l}0.23 * * \\
(0.20)\end{array}$ & $\begin{array}{l}0.60 * \\
(0.21)\end{array}$ & $\begin{array}{l}0.03 * \\
(0.29)\end{array}$ & $\begin{array}{l}0.68 * * \\
(0.15)\end{array}$ \\
\hline \multicolumn{9}{|c|}{ S4.LGDP-LMR-LPOP65 } \\
\hline LGDP & $\begin{array}{l}0.82 * * * \\
(0.04)\end{array}$ & $\begin{array}{l}0.39 * * * \\
(0.05)\end{array}$ & $\begin{array}{l}0.79 * * * \\
(0.04)\end{array}$ & $\begin{array}{l}0.59 * * * \\
(0.02)\end{array}$ & $\begin{array}{l}0.73 * * * \\
(0.01)\end{array}$ & $\begin{array}{l}0.48 * * * \\
(0.31)\end{array}$ & $\begin{array}{l}0.81 * * * \\
(0.06)\end{array}$ & $\begin{array}{l}0.64 * * * \\
(0.08)\end{array}$ \\
\hline LMR & $\begin{array}{l}-0.57 * * * \\
(0.17)\end{array}$ & $\begin{array}{l}-0.90 * * \\
(0.05)\end{array}$ & $\begin{array}{l}-0.66^{* * *} \\
(0.22)\end{array}$ & $\begin{array}{l}-0.38 * * \\
(0.12)\end{array}$ & $\begin{array}{l}0.32 * * \\
(0.04)\end{array}$ & $\begin{array}{l}-2.18 * * \\
(0.64)\end{array}$ & $\begin{array}{l}-0.33 * * \\
(0.05)\end{array}$ & $\begin{array}{l}-0.20 * * \\
(0.07)\end{array}$ \\
\hline LPOP65 & $\begin{array}{l}0.20 * * * \\
(0.22)\end{array}$ & $\begin{array}{l}0.29 * \\
(0.09)\end{array}$ & $\begin{array}{l}-0.19 \\
(-0.17)\end{array}$ & $\begin{array}{l}0.16 \\
(0.09)\end{array}$ & $\begin{array}{l}0.40 * * \\
(0.00)\end{array}$ & $\begin{array}{l}0.36^{*} \\
(0.23) \\
\end{array}$ & $\begin{array}{l}-0.08 \\
(0.20)\end{array}$ & $\begin{array}{l}0.97 * \\
(0.37) \\
\end{array}$ \\
\hline
\end{tabular}

Note: $*, * *$ and $* * *$ denote statistical significance at the $1 \%, 5 \%$ and $10 \%$ levels, respectively. Standard error is betwe parentheses.

Table 5 also reports the estimation results of PMG and CCE estimation for the three subgroups namely, high-income countries (GCC countries), upper-middle countries and lower-middle-income countries.

As shown in Table 5, the two different estimations reveal positive and significant income coefficients for all groups, at $1 \%$ and 5\% level of significance. Furthermore, all income elasticities are less than 1 indicating that health care is a necessity good for the three groups. Surprisingly, the results show that health care is a necessity good even in the GCC countries, contrary to our expectations that for these rich countries, health care would be a luxury good, as it is the case in the rich OECD countries. These results point out that even in the richest region of the Arab world, the per capita health spending is still lower than OECD countries. Moreover, according to IMF (2014), this region is also facing major infrastructure problems combined with growing expatriates populations, particularly in Qatar, UAE, and Kuwait, adding more pressure to the health sector. It should be noted, however, that the results show (S4 Model) an income elasticity in the lower-middle-income countries higher than in the high-income countries for both estimations. These results are in line with Baltagi et al. (2016) and Zhang (2013) in which an increase level of wealth is 
accompanied with positive and strong responsiveness of income elasticity, particularly in low-income countries compared to high-income countries. This may be explained by the differences in the health care systems structures, the aims of the health care systems in terms of ensuring a healthy lifestyle and the promotion of the well-being of the population, and the differences in the health care productivities.

The estimated coefficients of technological effect proxied by life expectancy and aging population in the models $\mathrm{S} 2$ and $\mathrm{S} 3$ are also positive and significant in all cases. The mortality rate coefficient in S1 model, on the other hand and as expected is negative and significant for all cases. These results imply that technological progress is a major determinant of heath expenditure in the three income groups. Indeed, health care sector in the Arab world has seen significant growth over the last two decade with improvement in the quality of health services and infrastructure (Khoja et al., 2017). For instance, during the past few years in the GCC countries, significant investments in health care infrastructure were undertaken, such as building large medical cities ${ }^{4}$ and complexes, clinics and hospitals. These investments raised the quality of healthcare services in the region (Ram, 2014). According to the World Health Organization (2014), life expectancy in GCC countries has increased to 77 years and infant mortality is decreased to 8 deaths per 1,000 live births in 2013 .

Furthermore, faster medical progress is expected to increase total health expenditures in the three income groups. This link is robust for our different proxies of technological effect. For instance, the GCC countries, especially the UAE and Qatar, have one of the highest growth rates of healthcare costs due to the advent of new medical technologies, along with better healthcare facilities. New technologies such as e-health services are being increasingly adopted to improve the quality of health care services. Furthermore, in 2013, the Saudi Ministry of Health signed an agreement with the British Medical Journal, one of the world's most respected medical journals, for cooperation in health learning and research (Ram, 2014).

Regarding the ageing population variable, considered as a demographic measure in the model $\mathrm{S} 4$, the results are not conclusive. The variables are positive and significant only for the lower- and upper-middle-income groups either in the CCE or PMG estimations. The very low percentage of ageing population in the total population may explain the insignificance of ageing population variable for the GCC countries. Alrouh et al (2013) point out that the GCC countries have the lowest age dependency ratios in the world. For example, Qatar and UAE age dependency ratios are around 17 and $21 \%$, respectively. In addition, this region is experiencing a rapid expatriates population growth, thus impacting the population structure.

\footnotetext{
${ }^{4}$ The Saudi Arabian government is currently building 5 important healthcare related projects. We can cite two major project, the King Fahad Medical City, consisting of four hospitals with a total of more than one thousand beds and different primary care clinics. The second one is the new Sheikh Khalifa Medical City consisting of three hospitals with a total of 838 beds, spread over 300,000 square meters.
} 
As for the short run relationship between total health expenditure and its determinant, the results of using the PMG estimators for the model S4 are reported in Table 6.

We observe from the results that the Error Correction Term (ECT) is negative and significant for the whole panel, as well as for the three groups. Looking at the short run estimations reveals that only income coefficient is positive and significant for the panel, indicating that total health expenditure reacts to short run variation of income in the Arab world countries. Nevertheless, we find that only the mortality rate is negative and significant for the upper middle-income group. The proxy for technological progress (LMR), and ageing population variable are statically insignificant for both the panel and the sub-samples. This results can be explained by the fact that advances in medical technology and changes in the ageing population takes a long time to yield their benefits or impose their effects (Murthy \& Ketenci, 2017).

Table 6: PMG, Short Run Estimation.

\begin{tabular}{lllll}
\hline & Panel & GCC & UMI & LMI \\
\hline Short-run & ARDL 2.2.2.2 & ARDL 1.1.1.1 & ARDL 1.2.2.2 & ARDL 1.1.1.1 \\
S4.LGDP-LMR-LPOP65 & Coefficient & Coefficient & Coefficient & Coefficient \\
ECT(-1) & $-0.62^{* * *}$ & $-0.30^{* * *}$ & $-0.49^{* * *}$ & $-0.32^{* * * *}$ \\
D.LTHE(-1) & 0.13 & & -0.85 & \\
D.LGDP & 0.80 & -0.56 & & 0.90 \\
D.LGDP(-1) & $0.38^{*}$ & & -0.61 & \\
D.LPOP65 & 1.80 & 1.92 & -0.65 & 2.95 \\
D.LPOP65(-1) & 3.54 & & 0.92 & -0.15 \\
D.LMR & -1.07 & -0.60 & 2.29 & \\
D.LMR(-1) & 2.05 & & $0.33^{* *}$ & \\
\hline
\end{tabular}

$*, * *$ and $* * *$ denote statistical significance at the $1 \%, 5 \%$ and $10 \%$ levels, respectively.

Model selection method: Akaike info criterion (AIC).

To complement our findings, we employ the Granger causality test developed by Dumitrescu \& Hurlin (2012), which is robust to heterogeneity and cross-sectional dependence across countries.

\subsection{Pairwise Dumitrescu-Hurlin panel causality}

To better understand the relationship between health spending and its determinants, we also investigate the existence of a causality between total health spending and its determinants, and test the presence of bilateral causality between health spending and income. We use a recently developed test by Dumitrescu \& Hurlin (2012). This test is a simple Granger (1969) non-causality test in heterogeneous panel data models. This test, conducted by running a standard Granger causality regression for each cross-section individually, allows all coefficients to be different through the cross-section and takes the average of the test statistics across the cross-sectional units. The results are presented in Table 7.

By observing the results, we see that the panel estimation reveals the existence of a bilateral relationship between total health spending and its determinants. The existence of a bidirectional relationship between THE and GDP is crucial for policy makers, confirming the conclusions of previous 
studies, which pointed out that increasing health care expenditure tends to increases social security, tranquillity, safety, and welfare, leading to improved labour efficiency, economic growth and quality of life (Amiri \& Ventelou, 2012; Murthy \& Okunade, 2009). The results also show that elderly population causes total health spending to increase, implying that ageing population represents a big challenge for the Arab words countries in the long run.

It is important to highlight the existence of bidirectional relationship between THE and GDP for the three income groups.

Table 7. Pairwise Dumitrescu-Hurlin Panel Causality.

\begin{tabular}{|c|c|c|c|c|c|c|c|c|}
\hline \multirow{2}{*}{ Direction of Causality } & \multicolumn{2}{|c|}{ Panel } & \multicolumn{2}{|c|}{ GCC } & \multicolumn{2}{|c|}{ UMI } & \multicolumn{2}{|c|}{ LMI } \\
\hline & W-Stat. & Zbar-Stat. & W-Stat. & Zbar-Stat. & W-Stat. & Zbar-Stat. & W-Stat. & Zbar-Stat. \\
\hline LGDP - LTHE & 2.90 & $5.71 * * *$ & 5.04 & $7.01 * * *$ & 3.17 & $3.07 * * *$ & 4.72 & $7.44 * * *$ \\
\hline LTHE -- LGDP & 4.84 & $10.46^{* * * *}$ & 2.31 & $2.28 * * *$ & 2.28 & $2.20 * * *$ & 3.51 & $5.03 * * *$ \\
\hline LLE-- LTHE & 13.53 & $37.59 * * *$ & 7.43 & $11.14 * * *$ & 22.36 & $30.21 * * *$ & 13.68 & $25.37 * * *$ \\
\hline LTHE -- LLE & 3.40 & $7.21 * * *$ & 1.61 & 1.06 & 2.43 & $2.03 * *$ & 5.22 & $8.45^{* * *}$ \\
\hline LMRI -- LTHE & 7.14 & $18.42 * * *$ & 4.05 & $5.25 * * *$ & 14.59 & $19.22 * * *$ & 5.73 & $9.46^{* * * *}$ \\
\hline LTHE -- LMRI & 4.16 & $9.48 * * *$ & 1.40 & -0.69 & 3.90 & $4.22 * * *$ & 6.32 & $10.46^{* * * *}$ \\
\hline LPOP65 -- LTHE & 3.60 & $7.82 * * *$ & 5.65 & $8.05^{* * * *}$ & 4.42 & $4.56^{* * * *}$ & 1.76 & 1.53 \\
\hline LTHE -- LPOP65 & 3.23 & $6.70 * * *$ & 0.61 & -0.65 & 2.23 & $1.73 *$ & 5.70 & $9.41 * * *$ \\
\hline
\end{tabular}

$* * *, * *$ and $*$ denote statistical significance at the $1 \%, 5 \%$ and $10 \%$ levels, respectively.

\section{Conclusion and implications}

Determining and understanding the factors driving health care expenditure remain an important and challenging task for academic researchers and policymakers. In this paper, we used two different techniques, the Pooled Mean Group estimator (PMG), and the Common Correlated effects (CCE) estimator to better understand the long run driving factors of total health spending for 18 Arab world countries over the period 1995-2015. We conducted the same estimations for 3 sub-samples namely, high-income (GCC countries), upper-middle- and lower-middle-income countries to count for the heterogeneity between them. Our empirical findings show that health care expenditure and its determinants are non-stationary and revealed the existence of a long run relationship among the considered variables. Furthermore, the estimation results suggest that income is not the only driver of health expenditure in Arab world countries in the long run. Other variables such as, technological progress measured by mortality rate or life expectancy, and ageing population are also playing an important role in the increase of health care expenditure, with major implications for the region in the long run. In the short run, the result show that the growth of health care spending is also affected by the variation of income. 
Moreover, the main finding of this study is that health care in the Arab world countries is a necessity good rather than a luxury one. This finding is also confirmed in the sub-samples analysis. In addition, our study reveals that the elderly population will likely increase health care costs in the long term. To cope with this challenge, we suggest improving the healthcare programs, and intensifying preventive health campaigns related to diseases affecting old population, as strategies for containing elderly health care costs.

Our results also show that other factors than the ageing population are expected increase the demand for health care services and create additional challenge in the region. These factors, include the advancement in medical technologies, in the form of decreased mortality rate and increased life expectancy in the Arab world.

Finally, the causality analysis shows that the relationship between total health care expenditure and GDP is bidirectional, thus implying that increasing health care expenditure leads to a higher labour efficiency, economic growth, and a better quality of life. In light of these results, the improvement of the health condition in the Arab countries should be a priority in their development policies, as such improvements as well as investments in human capital in general, play a decisive role in the achievement of their development process.

\section{References}

Abdullah, S. M., Siddiqua, S., \& Huque, R. (2017). Is health care a necessary or luxury product for Asian countries? An answer using panel approach. Health Economics Review, 7(1). https://doi.org/10.1186/s13561-017-0144-8

Alrouh, H., Ismail, A., \& Cheema, S. (2013). Demographic and health indicators in Gulf Cooperation Council nations with an emphasis on Qatar. Journal of Local and Global Health Perspectives, 3.

Amiri, A., \& Ventelou, B. (2012). Granger causality between total expenditure on health and gdp in OECD: evidence from the Toda-Yamamoto approach. Economics Letters, 116, 541-544.

Baker, L. C., \& Wheeler, S. K. (1998). Managed care and technology diffusion: the case of MRI. Health Affairs, 17(5), 195-207. https://doi.org/10.1377/hlthaff.17.5.195

Baltagi, B. H., Lagravinese, R., Moscone, F., \& Tosetti, E. (2016). Health Care Expenditure and Income: A Global Perspective. Health Economics.

Baltagi, B. H., \& Moscone, F. (2010). Health care expenditure and income in the OECD reconsidered: Evidence from panel data. Economic Modelling, 27(4), 804-811. https://doi.org/10.1016/j.econmod.2009.12.001

Barkat, K., Mrabet, Z., \& Alsamara, M. (2016). Does Official Development Assistance for health from developed countries displace government health expenditure in Sub-Saharan countries? Economics Bulletin, 36(3), 16161635.

Blomqvist, Å. G., \& Carter, R. A. L. (1997). Is health care really a luxury? Journal of Health Economics, 16(2), 207229. https://doi.org/10.1016/S0167-6296(96)00534-6

Borisch, B. (2013). Public health in the Arab World: at a crossroads. Journal of Public Health Policy, 34(2), 356-60. https://doi.org/10.1057/jphp.2013.2

Bousmah, M.-A.-Q., Ventelou, B., \& Abu-Zaineh, M. (2016). Medicine and democracy: The importance of institutional quality in the relationship between health expenditure and health outcomes in the MENA region. 
Health Policy, 120(8), 928-935. https://doi.org/10.1016/j.healthpol.2016.06.005

Breitung, J. (2005). A Parametric approach to the Estimation of Cointegration Vectors in Panel Data. Econometric Reviews, 24(2), 151-173. https://doi.org/10.1081/ETC-200067895

Chaabouni, S., \& Abednnadher, C. (2014). The determinants of health expenditures in Tunisia: An ARDL bounds testing approach. International Journal of Information Systems in the Service Sector (IJISSS), 6(4), 60-72. https://doi.org/10.4018/978-1-5225-3168-5.ch015

Chaabouni, S., \& Saidi, K. (2017). The dynamic links between carbon dioxide (CO2) emissions, health spending and GDP growth: A case study for 51 countries. Environmental Research, 158(May), 137-144. https://doi.org/10.1016/j.envres.2017.05.041

Culyer, A. J. (1988). Health care expenditures in Canada : myth and reality, past and future. Toronto : Canadian Tax Foundation.

Di Matteo, L. (2003). The income elasticity of health care spending: A comparison of parametric and nonparametric approaches. European Journal of Health Economics, 4(1), 20-29. https://doi.org/10.1007/s10198-002-0141-6

Di Matteo, L., \& Di Matteo, R. (1998). Evidence on the determinants of Canadian provincial government health expenditures: 1965-1991. Journal of Health Economics, 17(2), 211-228. https://doi.org/10.1016/S01676296(97)00020-9

Dreger, C., \& Reimers, H.-E. (2005). Health Care Expenditures in OECD Countries: A Panel Unit Root and Cointegration Analysis. International Journal of Applied Econometrics and Quantitative Studies, 2(2), 5-20. Retrieved from http://ideas.repec.org/p/iza/izadps/dp1469.html

Dumitrescu, E. I., \& Hurlin, C. (2012). Testing for Granger Non- Causality in Heterogeneous Panels. Economic Modelling, 29(4), 1450-1460.

Elk, R. van, Mot, E., \& Franses, P. H. (2009). Modelling health care expenditures; overview of the literature and evidence from a panel time series model. CPB Discussion Paper. CPB Netherlands Bureau for Economic Policy Analysis.

Erdodu, M., \& Christiansen, B. (Eds.). (2016). Handbook of Research on Public Finance in Europe and the MENA Region. Hershey, PA: Business Science Reference.

Freeman, D. G. (2003). Is health care a necessity or a luxury? Pooled estimates of income elasticity from US statelevel data. Applied Economics, 35(5), 495-502. https://doi.org/10.1080/00036840210138374

Gerdtham, U. G., \& Jönsson, B. (2000). International comparisons of health expenditure: Theory, data and econometric analysis. In A. J. Culyer \& J. P. Newhouse (Eds.), Handbook of Health Economics (Vol. 1, pp. 1153). Amsterdam: Elsevier. https://doi.org/10.1016/S1574-0064(00)80160-2

Gerdtham, U. G., \& Löthgren, M. (2000). On stationarity and cointegration of international health expenditure and GDP. Journal of Health Economics. https://doi.org/10.1016/S0167-6296(99)00036-3

Gerdtham, U. G., \& Löthgren, M. (2002). New panel results on cointegration of international health expenditure and GDP. Applied Economics, 34(13), 1679-1686. https://doi.org/10.1080/00036840110116397

Gerdtham, U. G., Søgaard, J., Andersson, F., \& Jönsson, B. (1992). An econometric analysis of health care expenditure: a cross-section study of the OECD countries. Journal of Health Economics, 11, 63-84. https://doi.org/10.1016/0167-6296(92)90025-V

Granger, C. W. J. (1969). Investigating causal relations by econometric models and cross-spectral methods. Econometrica, 37, 424-438.

Hassan, M., \& Kalim, R. (2012). The Triangular Causality Among Education, Health and Economic Growth : A Time Series Analysis of Pakistan. World Applied Sciences Journal, 18(2), 196-207. https://doi.org/10.5829/idosi.wasj.2012.18.02.3332 
Hirnissa, M. T., Habibullah, M. S., \& Baharom, A. H. (2009). The Relationship between Defense, Education and Health Expenditures in Selected Asian Countries. International Journal of Economics and Finance, 1(2), 149155.

Retrieved

from http://ccsenet.org/journal/index.php/ijef/issue/archive\%5Cnhttp://search.ebscohost.com/login.aspx?direct=true $\& \mathrm{db}=\mathrm{ecn} \& \mathrm{AN}=1086011 \&$ site $=$ ehost-live $\&$ scope $=$ site

Hitiris, T., \& Posnett, J. (1992). The determinants and effects of health expenditure in developed countries. Journal of Health Economics, 11(2), 173-181. https://doi.org/10.1016/0167-6296(92)90033-W

Im, K. S., Pesaran, H. M., \& Shin, Y. (2003). Testing for unit roots in heterogeneous panels. Journal of Econometrics, 115(1), 53-74. https://doi.org/10.1016/S0304-4076(03)00092-7

International Monetary Fund. (2014). Regional Economic Outlook : Middle East and Central Asia (REO). Retrieved from https://www.imf.org/external/pubs/ft/reo/2014/mcd/eng/pdf/mreo1014.pdf

Jönsson, B., \& Eckerlund, I. (2003). Why do different countries spend different amounts on health care? In Diseasebased Comparison of Health Systems. Paris: OECD Publishing.

Khan, H. N., Khan, M. A., Razli, R. B., Sahfie, A. B., Shehzada, G., Krebs, K. L., \& Sarvghad, N. (2016). Health Care Expenditure and Economic Growth in SAARC Countries (1995-2012): A Panel Causality Analysis. Applied Research in Quality of Life, 11(3), 639-661. https://doi.org/10.1007/s11482-015-9385-z

Khoja, T., Rawaf, S., Qidwai, W., Rawaf, D., Nanji, K., \& Hamad, A. (2017). Health Care in Gulf Cooperation Council Countries: A Review of Challenges and Opportunities. Cureus, 9(8), e1586. https://doi.org/10.7759/cureus.1586

Klautzer, L., Becker, J., \& Mattke, S. (2014). The curse of wealth - Middle Eastern countries need to address the rapidly rising burden of diabetes. International Journal of Health Policy and Management, 2(3), 109-14. https://doi.org/10.15171/ijhpm.2014.33

Kleiman, E. (1974). The determinants of national outlay on health. In The economics of health and medical care (pp. 66-88). UK: Palgrave Macmillan.

Leu, R. E. (1986). The public-private mix and international health care costs: a cross-country comparison. In B. Jönsson \& A. J. Culyer (Eds.), Public and private health services : complementarities and conflicts (pp. 41-63). Oxford: Basil Blackwell.

Lv, Z., \& Zhu, H. (2014). Health Care Expenditure and GDP in African Countries : Evidence from Semiparametric Estimation with Panel Data, 2014.

Mehmood, B., Raza, S. H., \& Mureed, S. (2014). Health Expenditure , Literacy and Economic Growth: PMG Evidence from Asian Countries. Euro-Asian Journal of Economics and Finance, 0184(October), 408-417.

Moscone, F., \& Tosetti, E. (2010). Health expenditure and income in the United States. Health Economics, 19(12), 1385-1403. https://doi.org/10.1002/hec.1552

Murthy, V. N. R., \& Ketenci, N. (2017). Is technology still a major driver of health expenditure in the United States? Evidence from cointegration analysis with multiple structural breaks. International Journal of Health Economics and Management, 17(1), 29-50. https://doi.org/10.1007/s10754-016-9196-2

Murthy, V. N. R., \& Okunade, A. A. (2009). The core determinants of health expenditure in the African context: Some econometric evidence for policy. Health Policy, 91(1), 57-62. https://doi.org/10.1016/j.healthpol.2008.10.001

Murthy, V. N. R., \& Okunade, A. A. (2016). Determinants of U.S. health expenditure: Evidence from autoregressive distributed lag (ARDL) approach to cointegration. Economic Modelling, 59, 67-73.

Nasiru, I., \& Usman, H. M. (2012). Health Expenditure and Economic Growth Nexus: An ARDL Approach for the case of Nigeria. Journal of Research in National Development, 10(3), 95-100.

Newhouse, J. P. (1977). Medical-care expenditure: a cross-national survey. Journal of Human Resources, 12(1), 115125. https://doi.org/10.2307/145602 
Okunade, A. A., Karakus, M. C., \& Okeke, C. (2004). Determinants of health expenditure growth of the OECD countries: Jackknife resampling plan estimates. Health Care Management Science, 7(3), 173-183. https://doi.org/10.1023/B:HCMS.0000039380.42784.20

Okunade, A. A., \& Murthy, V. N. R. (2002). Technology as a "major driver" of health care costs: A cointegration analysis of the Newhouse conjecture. Journal of Health Economics, 21(1), 147-159. https://doi.org/10.1016/S0167-6296(01)00122-9

Okunade, A. A., You, X., \& Koleyni, K. (2018). Cross-country Medical Expenditure Modeling Using OECD Panel Data and ARDL Approach: Investigating GDP, Technology, and Aging Effects, 327-358. https://doi.org/10.1108/S0573-855520180000294018

Pesaran, H. M. (2004). 'General Diagnostic Tests for Cross Section Dependence in Panels' (Cambridge Working Papers in Economics No. 0435). Faculty of Economics, University of Cambridge.

Pesaran, H. M. (2006). Estimation and Inference in Large Heterogeneous Panels with a Multifactor Error Structure. Econometrica, 74(4), 967-1012. https://doi.org/10.2307/3805914

Pesaran, H. M. (2007). A simple panel unit root test in the presence of cross-section dependence. Journal of Applied Econometrics, 22(2), 265-312. https://doi.org/10.1002/jae.951

Pesaran, H. M., Shin, Y., \& Smith, R. (1999). Pooled mean group estimation of dynamic heterogeneous panels. Journal of the American Statistical Association, 446(94), 621-634.

Pesaran, H. M., \& Yamagata, T. (2008). Testing slope homogeneity in large panels. Journal of Econometrics, 142(1), 50-93. https://doi.org/10.1016/J.JECONOM.2007.05.010

Rahman, M. M. (2011). Causal Relationship among Education Expenditure, Health Expenditure and GDP: A Case Study for Bangladesh. International Journal of Economics and Finance, 3(3), 149-159. https://doi.org/10.5539/ijef.v3n3p149

Ram, P. (2014). Management of Healthcare in the Gulf Cooperation Council ( GCC ) countries with special reference to Saudi Arabia. International Journal of Academic Research in Business and Social Sciences, 4(12), 24-41.

Roberts, J. (1999). Sensitivity of elasticity estimates for OECD health care spending: Analysis of a dynamic heterogeneous data field. Health Economics, 8(5), 459-472. https://doi.org/10.1002/(SICI)10991050(199908)8:5<459::AID-HEC454>3.0.CO;2-U

Swamy, P. A. (1970). Efficient Inference in a Random Coefficient Regression Model. Econometrica, 38(2), 311-323.

Tang, C. F., \& Ch'ng, K. S. (2011). “ The Granger causality between health expenditure and income in Southeast Asia economies ." African Journal of Business Management, 5(16), 6814-6824. https://doi.org/10.5897/AJBM10.1550

Tang, C. F., \& Lai, Y. W. (2011). The Causal Relationship between Health and Education Expenditures in Malaysia. Theoretical and Applied Economics, 18(8), 61-74. Retrieved from http://www.ectap.ro/theoretical-and-appliedeconomicsarchive/\%5Cnhttp://search.ebscohost.com/login.aspx?direct=true\&db=ecn\&AN=1264387\&site=ehostlive\&scope $=$ site

United Nation. (2015). World Population Prospects: The 2015 Revision. Retrieved from https://esa.un.org/unpd/wpp/ Westerlund, J. (2007). Testing for Error Correction in Panel Data. Oxford Bulletin of Economics and Statistics, 69(6), 709-748. https://doi.org/10.1111/j.1468-0084.2007.00477.x

World Bank. (2015). International Comparison Program database. Retrieved from http://data.worldbank.org/indicator/NY.GDP.PCAP.PP.CD?year_high_desc=true

World Health Organization. (2014). World Health Statistics 2014. Geneva, Switzerland.

Yavuz, N. C., Yilanci, V., \& Ozturk, Z. A. (2013). Is health care a luxury or a necessity or both? Evidence from 
Turkey. European Journal of Health Economics, 14(1), 5-10. https://doi.org/10.1007/s10198-011-0339-6

Yorulmaz, Ö. (2016). Can healthcare ever be less than a necessity in MENA countries? A semiparametric estimation of the relationship between healthcare expenditure and GDP. Quality \& Quantity, 50(3), 1233-1244. https://doi.org/10.1007/s11135-015-0201-5

You, X., \& Okunade, A. A. (2017). Income and Technology as Drivers of Australian Healthcare Expenditures. Health economics. Health Economics, 26(7), 853-862. https://doi.org/10.1002/hec

Zhang, L. (2013). Income Growth and Technology Advance: The Evolution of the Income Elasticity of Health Expenditure (Working Paper, University of Oslo). 